http://dx.doi.org/10.18675/1981-8106.vol25.n48.p54-66

\title{
Responsabilização ou controle da qualidade do ensino: a que serve a avaliação externa?
}

\section{Accountability or control the quality of education: it serves the external evaluation?}

\section{Responsabilización o control de la calidad de la enseñanza: ¿para qué sirve la evaluación externa?}

\author{
Cristiane Machado ' \\ Ocimar Munhoz Alavarse " \\ ' Universidade Cidade de São Paulo (UNICID), São Paulo - Brasil. E-mail: \\ cristiane13machado@yahoo.com.br \\ "Universidade de São Paulo (USP), São Paulo - Brasil. E-mail: ocimar@usp.br
}

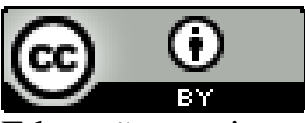

Educação: teoria e prática, Rio Claro, SP, Brasil - eISSN: 1981-8106

Está licenciada sob Licença Creative Common

\section{Resumo}

No Brasil, assim como em outros países, constata-se a consolidação das avaliações externas como iniciativas de políticas educativas governamentais, tendo como principal objeto o desempenho de alunos em leitura e resolução de problemas. Seus resultados, também, têm servido de base para avaliação de escolas e professores, incluindo políticas de bonificação. Nesse sentido, ao identificar a qualidade do desempenho dos alunos em provas padronizadas como responsabilidade quase que exclusiva das equipes escolares, a avaliação externa tornase uma política de accountability, ou seja, de responsabilização. Contudo, pondera-se, neste trabalho, que os resultados das avaliações externas permitem, por outro lado, estabelecer um controle da qualidade do ensino, no sentido de acompanhamento da aprendizagem dos alunos e do trabalho desenvolvido pelas equipes escolares.

Palavras-chave: Avaliação externa; Responsabilização; Qualidade; Aprendizagem. 


\begin{abstract}
In Brazil, as in other countries, there is the consolidation of external evaluation of educational policies and initiatives of government, having as main object the performance of students in reading and problem solving. Their results also have served as a basis for evaluating schools and teachers, including subsidy policies. Accordingly, to identify the quality of student performance on standardized tests such as the almost exclusive responsibility of school staff to external evaluation becomes a policy of accountability, or responsabilization. However, considering in this work, the results of external assessments may, on the other hand, establish a quality control of teaching, to monitor the students learning and the work done by school staff.
\end{abstract}

Keywords: External evaluation; Accountability; Quality; Learning.

\title{
Resumen
}

En Brasil, así como en otros países, se constata la consolidación de las evaluaciones externas como iniciativas de políticas educativas gubernamentales, teniendo como principal objeto el desempeño de alumnos en lectura y resolución de problemas. Sus resultados, también han servido de base para la evaluación de escuelas y profesores, incluyendo políticas de bonificación. En ese sentido, al identificar la calidad del desempeño de los alumnos en pruebas estandarizadas como responsabilidad casi que exclusiva de los equipos escolares, la evaluación externa se vuelve una política de accountability, o sea, de responsabilización. Sin embargo, se pondera, en este trabajo, que los resultados de las evaluaciones externas permiten, por otro lado, establecer un control de calidad de enseñanza, en el sentido de acompañamiento del aprendizaje de los alumnos y del trabajo desarrollado por los equipos escolares.

Palabras clave: Evaluación externa; Responsabilización; Calidad; Aprendizaje.

\section{Introdução}

Observa-se, no contexto educacional mundial, a ampliação e fortalecimento de iniciativas de criação de sistemas nacionais de avaliação externa. O Brasil entra definitivamente nessa tendência na década de 1990, com a implantação do Sistema de Avaliação da Educação Básica (Saeb). Em geral, os sistemas de avaliação têm como foco principal a aferição do desempenho dos alunos em provas padronizadas de língua portuguesa (foco em leitura) e matemática (foco em resolução de problemas).

Franco, Alves e Bonamino (2007, p. 990) analisam que nesse momento, também, foi revigorado o debate sobre a qualidade da educação, pois o avanço na universalização do ensino fundamental aliado à disponibilização dos dados gerados pelo sistema de avaliação 
trouxe questionamentos sobre a qualidade do ensino oferecido para a grande maioria da população escolar, o que impulsionou muitos pesquisadores e gestores a engendrarem investigações sobre o tema.

A partir de então, observa-se diferentes apreensões da realidade educacional e das consequências das iniciativas de avaliação externa. Por um lado, estudos apontam para a possibilidade de utilizar essas ações como mecanismo de responsabilização e/ou prestação de contas, também chamado de accountability, por outro, pesquisadores destacam a importância de viabilizar a melhoria na qualidade da educação a partir da apropriação reflexiva dos dados e informações obtidos com as aferições feitas.

Neste estudo analisa-se que, mesmo a qualidade do trabalho escolar não se resumindo e nem se esgotando no desempenho dos alunos nas provas padronizadas, essas avaliações externas permitem conduzir uma análise do trabalho feito, estabelecendo um tipo de controle da qualidade do ensino, no sentido de criar condições para que todos tenham acesso a uma educação pública de qualidade, uma vez que tais resultados representam importantes dimensões dos objetivos escolares, a saber, desempenho em leitura e resolução de problemas e aprovação dos alunos.

As informações e dados produzidos pelas avaliações externas podem, assim, desempenhar um papel estratégico na possibilidade de conhecimento e reflexão sobre o desempenho dos alunos nos conteúdos avaliados nas provas padronizadas, bem como para o estudo e a proposição de ações pelas gestões dos sistemas, inclusive pelo fato de que disponibilizam dados referenciais para que escolas e redes tenham marcos comparativos entre si, e de cada unidade educacional consigo própria, favorecendo a construção de alternativas para a melhoria da qualidade da educação, não sendo possível, contudo, uma associação direta entre trabalho docente e esses resultados.

\section{Trajetória da avaliação externa no Brasil: entre a responsabilização e o controle para a melhoria da qualidade}

Analisar a trajetória da constituição do principal sistema de avaliação externa do país, o Saeb, nos remete aos anos 1930, quando o Estado intencionou desenvolver pesquisas e estudos na perspectiva de subsidiar a política educacional. Porém, foi só em 1987 que o Ministério da Educação (MEC) criou o Sistema de Avaliação do Ensino Público de $1^{\circ}$ Grau (Saep), com o objetivo de avaliar o Programa de Educação Básica para o Nordeste, e atribui ao Instituto Nacional de Estudos e Pesquisas Anísio Teixeira (Inep) sua organização e execução (COELHO, 2008; FREITAS, 2007; BONAMINO, 2002). Posteriormente, em 1990, o reconhecimento da importância de obter informações sobre o sistema educacional como um todo levou o governo a transformar o Saep em Saeb.

No campo da avaliação educacional essa especificidade de processo avaliativo, a avaliação externa, pode ser definida como todo procedimento que comporta, além da avaliação propriamente dita, a medida das proficiências dos alunos em provas padronizadas, o que pode produzir, também, resultados por escolas e redes. No entanto, a caracterização mais saliente para designá-la como externa é o fato de que essa avaliação é empreendida por sujeitos externos ao ambiente escolar. Em face de suas dimensões, geralmente é também 
chamada de avaliação em larga escala, pois abrange grande contingente de participantes e fornece subsídios para diversas ações e políticas educacionais para um amplo conjunto de escolas e redes.

Em 1995, o Saeb foi reformulado e sofreu mudanças significativas. Incluiu estudos e análises dos alunos do ensino médio e da rede particular; incorporou levantamentos de dados sobre as características socioeconômicas, culturais e sobre os hábitos de estudo dos alunos e redefiniu as séries avaliadas por amostragem, $4^{\mathrm{a}}$ e $8^{\mathrm{a}}$ séries do ensino fundamental e $3^{\mathrm{a}}$ série do ensino médio (COELHO, 2008). Além disso, introduziu a metodologia da Teoria de Resposta ao Item (TRI) para medir o desempenho dos alunos, possibilitando "comparações entre as diversas aplicações, criando-se, assim, uma série histórica, permitindo a elaboração de políticas públicas a longo prazo" (SOUSA; ARCAS, 2010, p. 182).

Em 2005, o Sistema foi desdobrado em duas avaliações. Uma delas, a Avaliação Nacional da Educação Básica (Aneb), manteve do Saeb seu desenho original de avaliação por amostragem. A outra, Avaliação Nacional do Rendimento Escolar (Anresc), conhecida com o nome de Prova Brasil, foi projetada para aplicação censitária de suas provas em todas as escolas públicas de ensino fundamental. O site do MEC/Inep (BRASIL, 2015) justifica sua ação, esclarecendo que a Aneb e a Prova Brasil "são dois exames complementares que compõem o Sistema de Avaliação da Educação Básica" e possuem semelhanças, como: são duas avaliações aplicadas a cada dois anos e nas quais os alunos fazem provas que avaliam as habilidades em Língua Portuguesa (foco em leitura) e Matemática (foco na resolução de problemas). Mas, adverte o MEC, também existem diferenças entre elas, como: a Prova Brasil avalia, censitariamente, alunos dos $5^{\circ}$ e $9^{\circ}$ anos do ensino fundamental de escolas públicas urbanas enquanto a Aneb avalia, por amostragem, alunos dos $5^{\circ}$ e $9^{\circ}$ anos do ensino fundamental de escolas privadas urbanas e alunos, de escolas públicas e privadas, do $3^{\circ}$ ano do ensino médio, da rede privada. Alerta o MEC que, em função de sua metodologia avaliativa, nenhum aluno precisará fazer as duas provas.

Cabe ressaltar que, uma diferença entre as duas avaliações, tem importância crucial para a gestão das escolas e a sociedade em geral. Enquanto o Saeb, até 2003, e agora a Aneb são de aplicação amostral, a Prova Brasil é censitária, e o fato de todos os alunos de todas as escolas serem avaliados permite que os resultados desta sejam fornecidos por escola, ao passo que aquela apenas permite resultados por Unidade da Federação, para os extratos de dependência administrativa - federal, estadual, municipal e privada. Uma das alegações para adoção da forma censitária foi de que antes, com o Saeb, as equipes escolares não se reconheciam nos resultados da avaliação, o que deixaria de ocorrer quando cada escola tivesse seu resultado. A avaliação censitária da Prova Brasil possibilitou a criação, em 2007, do Ideb que estabelece um indicador de qualidade das escolas, no caso das públicas de ensino fundamental, e de redes de ensino, socialmente, com fortes repercussões pela publicização dos resultados e pelas metas estabelecidas até 2020 .

Sousa e Lopes (2010, p. 55), diante desse quadro, ponderam que a diferença entre as avaliações externas, uma ser amostral e a outra censitária, é uma considerável justificativa para a criação de outro sistema de avaliação com as características da Anresc, porém não é a 
única, pois, além disso, soma-se "à necessidade de fazer da avaliação um instrumento de gestão para/das unidades escolares levou à proposição da Prova Brasil, cujos resultados estão disponíveis para cada uma das redes e para cada escola".

Dados relatados no estudo de Bonamino e Sousa (2012, p. 379) evidenciam as diferentes possibilidades de inserção na sociedade das duas avaliações, tendo como base a diferença numérica do contingente de alunos avaliados nas aferições. Ressaltam as autoras que

A introdução da Prova Brasil em 2005, e sua repetição, a cada dois anos, permitem a comparação, ao longo do tempo, entre as escolas que oferecem o ensino fundamental. Em sua primeira edição, ela avaliou mais de 3 milhões de alunos em aproximadamente 45.000 escolas urbanas de 5.398 municípios; foi muito além, portanto, do Saeb, que avalia, em média, uma amostra de 300.000 alunos.

Reynaldo Fernandes (2007, p.06), presidente do Inep à época da criação do Ideb, explicitou que esse índice estava sendo criado para ser "um indicador de qualidade educacional" e também para possibilitar um "monitoramento permanente e medição do progresso dos programas em relação às metas e resultados fixados" na educação brasileira.

O Ideb atingiu tal peso na educação brasileira que figura como proposta para ser o principal indicador da qualidade nacional no Plano Nacional de Educação. Diz o texto, em sua versão original:

Art. 11 O Índice de Desenvolvimento da Educação Básica - Ideb será utilizado para avaliar a qualidade do ensino a partir dos dados de rendimento escolar apurados pelo censo escolar da educação básica, combinados com os dados relativos ao desempenho dos estudantes apurados na avaliação nacional do rendimento escolar.

O MEC disponibiliza, a cada dois anos, o Ideb dos estados, municípios e escolas, obtido a partir das taxas de aprovação e das proficiências dos alunos na Prova Brasil, normalizadas numa escala de notas de 0 a 10. Também, a partir desses dados, o MEC projeta as metas a serem alcançadas para cada um desses segmentos.

Devemos destacar que a divulgação dos resultados da Prova Brasil e do Ideb tem possibilitado, aos meios jornalísticos, a divulgação das melhores (e consequentemente das piores!) escolas e sistemas do país em forma de ranking, corroborando uma cultura classificatória, inclusive, muito presente nas escolas. A nosso ver, essa apropriação dos dados, desatrelada de outras análises, é equivocada, pois impele as escolas e as redes à competição e não ao estudo minucioso da realidade educacional e suas dificuldades. Nesse sentido, defendemos que a avaliação deve ser utilizada com outro referencial, assim como explicita Vianna (2005, p. 16)

A avaliação não é um valor em si e não deve ficar restrita a um simples rito da burocracia educacional; necessita integrar-se ao processo de transformação do ensino/aprendizagem e contribuir, desse modo, ativamente, para o processo de transformação dos educandos. 
Oficialmente, o Ideb surge com o Plano de Metas e Compromisso Todos pela Educação, por meio do Decreto $n^{\circ}$ 6.094, de 24 de abril de 2007, e foi enfatizado como um dos aspectos mais relevantes do Plano de Desenvolvimento da Educação (PDE) por Fernando Haddad (2008, p. 11), então Ministro da Educação. Tal apreciação é corroborada por Saviani (2007, p. 1242-3), para quem

O que confere caráter diferenciado ao Ideb é a tentativa de agir sobre o problema da qualidade do ensino ministrado nas escolas de educação básica, buscando resolvê-lo. E isso veio ao encontro dos clamores da sociedade diante do fraco desempenho das escolas à luz dos indicadores nacionais e internacionais do rendimento dos alunos.

Esses clamores adquiriram maior visibilidade com as manifestações daquela parcela social com mais presença na mídia, em virtude de suas ligações com a área empresarial. Tal parcela só mais recentemente vem assumindo a bandeira da educação, em contraste com os educadores que apresentam uma história de lutas bem mais longa.

Na mesma perspectiva encontramos contribuições de Weber (2008, p. 312) ao admitir que

\begin{abstract}
Além disso, a fixação de metas em relação ao Índice de Desenvolvimento da Educação Básica - Ideb -, mediante consulta a banco de dados e visitas de inspeção, conduzirá evidentemente ao acompanhamento contínuo do processo escolar, não sendo possível antever em detalhes o seu formato, embora fique patente a importância atribuída às condições escolares, tanto materiais como pedagógicas. Ora, condições materiais dependem, certamente, das condições socioeconômicas de onde estão localizadas as unidades escolares, ou seja, primordialmente elas dependem de fatores extraescolares. As condições pedagógicas, se bem também se relacionem com o contexto social, remetem, por sua vez, a complexo aparato de formação docente - inicial e continuada -, acompanhamento e crítica da prática pedagógica, mas, sobretudo, à valorização da atividade docente consubstanciada em remuneração condizente e condições de trabalho adequadas - número de alunos por turma, jornada de trabalho, material didático disponível, incentivo ao intercâmbio, entre outros aspectos.
\end{abstract}

Como indicador, o Ideb, ao combinar os resultados de desempenho nas provas do Saeb com taxas de aprovação de cada uma das unidades - escolas e redes - para as quais é calculado, ressalta uma questão controversa que reside na concepção de qualidade da educação escolar que este indicador expressaria. Textualmente, no Decreto no 6.094 de 2007 a formulação do Ideb apresenta uma visão extremamente objetivista sobre o seu potencial para indicar a qualidade da escola:

Art. 3 A qualidade da educação básica será aferida, objetivamente, com base no Ideb, calculado e divulgado periodicamente pelo Inep, a partir dos dados sobre rendimento escolar, combinados com o desempenho dos alunos, constantes do censo escolar e do Sistema de Avaliação da Educação Básica - 
SAEB, composto pela Avaliação Nacional da Educação Básica - ANEB e a Avaliação Nacional do Rendimento Escolar (BRASIL, 2007, s/p).

Porém, há que se ressaltar a importância da definição oficial de qualidade, dada a "polissemia" (DOURADO, 2007, p. 07) e "ambiguidade" (RISOPATRON, 1991, p. 15) que o conceito envolve. Sousa (1997, p. 267) explica que "qualidade não é 'algo dado', não existe 'em si', remetendo à questão axiológica, ou seja, dos valores de quem produz a análise de qualidade". Para Dourado (2007, p. 09) qualidade da educação é "um fenômeno complexo, abrangente e que envolve múltiplas dimensões". Soares (2012, p. 83) define qualidade de uma forma mais específica, ao falar da escola. Para o autor

[...] escola de qualidade é aquela quem tem como valor fundamental a garantia dos direitos de aprendizagem de seus alunos, dispõe de infraestrutura necessária, ensina o que é relevante e pertinente através de processos eficazes e utiliza os recursos disponíveis, sem desperdícios. Seus professores e funcionários e os pais dos alunos estão satisfeitos e os alunos mostram, através de formas objetivas que aprenderam o que deles se esperava.

Nesse sentido, com base na lógica de criação do Ideb, entende-se que, para o governo federal uma educação de qualidade pode ser traduzida por bom desempenho em leitura e resolução de problemas e aprovação dos alunos.

Não obstante, se a conceituação do que seria a qualidade da escola, na literatura e nas políticas educacionais, não obteve ainda um consenso, somos, contudo, crescentemente, testemunhas de inflexões importantes a respeito do lugar que as avaliações externas passaram a ocupar nas políticas educacionais, destacadamente no plano federal, situação nitidamente evidenciada por Fernandes e Gremaud (2009, p. 213), os quais sinalizam com a necessidade de medidas de accountability - expressão inglesa traduzida como responsabilização - para que houvesse incidência dos resultados dessas avaliações nas escolas.

Embora a concepção de qualidade associada ao Ideb seja um tanto reducionista, por não contemplar aspectos relevantes do processo pedagógico, é possível considerar algumas potencialidades no Ideb, por conta de duas características: por facilitar uma apreensão, mesmo que parcial, da realidade educacional brasileira, aí destacadas suas escolas, e, sobretudo, por articular dois elementos que, há muito tempo, parecem ser antagônicos: o aumento da aprovação e o aumento do desempenho. Desse modo, admite-se que esses tópicos não são, de forma alguma, estranhos ao processo escolar que se pretenda como de qualidade, como já enfatizamos em passagem anterior.

Com efeito, o incremento do Ideb, a médio e a longo prazos, se dará pelo incremento desses dois fatores articulados com melhorias nas taxas de aprovação. Enquanto indicador, a questão consiste em dimensionar o seu potencial para contribuir no equacionamento e no enfrentamento de tarefas de planejamento educacional, uma vez que existem projeções do Ideb até 2020 para cada escola e rede, levando em conta, de alguma forma, as particularidades dessas unidades. 
Seguramente, a conceituação e o dimensionamento da qualidade da educação escolar se constituem num complexo problema político e pedagógico, pois concentram leituras da sociedade, da escola e das relações que entre elas se estabelecem. Oliveira e Araújo (2005) demarcam o debate, apontando a necessidade de que os resultados de avaliações externas sejam incorporados sem que, contudo, se estabeleça determinismo nas relações entre eles e o trabalho dos professores, como se estes fossem os únicos e plenamente capazes de engendrar os resultados escolares. Outra posição, representativa de várias iniciativas no Brasil no sentido de responsabilização, quase que exclusiva, dos professores pelos resultados, é a defendida por Castro (2007, p.61), para quem a qualidade da educação se expressa nos resultados de provas padronizadas e que, mesmo reconhecendo as precariedades na atividade docente, incluindo a sua remuneração, sustenta que a melhoria dos salários dos professores se daria pela "implantação de salários diferenciados mediante desempenho. Para isto, o ideal seria estabelecer sistemas de avaliação dos professores vinculados aos resultados das escolas". Em tal perspectiva, as avaliações externas, além da associação mecânica entre desempenho em provas e trabalho docente, desprezando, frequentemente, as condições das quais emergem esses resultados, confundem-se com um modelo de gerenciamento de recursos humanos, retirando-lhes todo o potencial pedagógico.

Oliveira (2011, p. 137), apoiando-se em Nevo (1998), destaca que as avaliações externas parecem ter sido desenhadas muito mais para produzir informações para os gestores de redes educacionais "do que para ajudar os professores a analisarem os resultados buscando rever seus métodos de ensino e práticas de avaliação". De acordo com a autora, "as comunicações de resultados das avaliações com foco na escola devem promover uma articulação com o trabalho pedagógico escolar de maneira a aprimorá-lo”.

Como alerta Gimeno Sacristán (1998, p. 320), a existência de avaliações externas pode comprometer, pela ênfase na crença de seus resultados como portadores da "última palavra", os necessários debates críticos sobre a situação educacional e seus procedimentos, além de submeter os professores a uma pressão externa, "subtraindo-lhes a autonomia profissional" e impedindo-os, contraditoriamente, de desenvolver trabalho mais profícuo com seus alunos. Frente a isto, coloca-se, como imperativa, a busca de um processo mais amplo de avaliação de escolas e redes que, para além da utilização de provas padronizadas, tenha presente o caráter político da educação escolar. Reconhecer esse caráter implica reconhecer profissionais e usuários das escolas como sujeitos que precisam ser considerados como tais nos processos avaliativos, pois, sem omitir-lhes as responsabilidades, são eles que, nos ambientes escolares, materializam a tarefa educativa.

Ainda no sentido de problematizações em face do desenfreado processo de incorporação das avaliações externas às políticas educacionais, é relevante o conjunto de ponderações efetuadas por Stobart (2010), que ressalva efeitos perversos e indesejáveis dessa modalidade de avaliação por se afastar das pretensões de uma avaliação para a aprendizagem, ou seja, que se constituiria num ponto para a inclusão com sucesso de todos os alunos concernidos à escolarização obrigatória. 
Afonso (2009, p.44) chama a atenção para o recrudescimento de mecanismos de responsabilização com a emergência das políticas neoliberais, após a década de 1980. Para o autor, "a avaliação dos sistemas educativos aparece doravante associada à responsabilização pelos resultados escolas dos alunos, sendo estes obtidos, sobretudo, pela utilização de testes estandardizados". Usar os resultados das avaliações externas como accountability é retirar desse instrumento diagnóstico todo seu sentido pedagógico e educativo, aniquilando seu potencial de incidir positivamente no ensino-aprendizagem para melhorar a qualidade do ensino. Nesse sentido, Freitas (2011, p. 19) assevera que "A associação dos testes com a ideologia da responsabilização e da meritocracia coloca-os como uma ferramenta de punição ou recompensa e confunde sua função central de diagnóstico da aprendizagem do aluno e da ação do professor".

A necessidade de encarar a avaliação, aliando-a ao desafio da aprendizagem, deriva do esforço de desvinculá-la dos mecanismos de aprovação ou reprovação e, mais importante, destaca outra finalidade da avaliação educacional, no que se concentra sua verdadeira dimensão política, pois numa escola que se pretenda democrática e inclusiva as práticas avaliativas deveriam se pautar por garantir que, no limite, todos aprendessem tudo. Ainda mais, quando nos reportamos ao ensino fundamental, etapa obrigatória, assim fixada para que a ninguém seja dado o direito de se excluir de conhecimentos considerados indispensáveis para o aproveitamento de outros direitos.

Se a qualidade na educação é um fenômeno complexo que possui determinações intraescolares, tais como currículo, formação docente, gestão escolar, avaliação da aprendizagem, condições de trabalho, infraestrutura das escolas etc., e extraescolares, tais como condições de vida da população, capital econômico, cultural e social das famílias dos alunos, entorno social da escola, distribuição de renda, violência, entre outros, o aumento do desempenho dos alunos nos exames é parte importante desse fenômeno, ainda que este não se esgote naquele, pois a medição da aprendizagem permite o aprofundamento do diagnóstico da situação da educação brasileira e o delineamento de iniciativas de políticas educacionais nesse terreno.

\section{Considerações finais}

Análises exploratórias sobre os resultados das escolas e das redes, a partir do estudo dos dados disponibilizados pelo Ideb, principalmente quando observados nas suas séries longitudinais, podem fazer a diferença para a escola cumprir seu papel de ensinar todos os seus alunos.

Reflexões com base nos dados gerados e disponibilizados pelo Ideb, tanto pela gestão de sistema com a gestão escolar, podem ser empreendidas nos espaços pedagógicos e no cotidiano da escola para lançar luzes sobre o trabalho que é realizado com o objetivo de avaliá-lo e, a partir desse movimento, estabelecer as metas e prioridades para a continuidade das ações coletivas nas redes e nas escolas na constante busca da melhoria da sua qualidade. 
A avaliação externa, especialmente a Prova Brasil, e sua articulação com a aprovação, como examinada aqui, fornece dados que, se apropriados de forma consistente, podem revigorar os contornos da escola pública que realiza a sua função social na sociedade democrática de garantir o ensino-aprendizagem para todos os seus alunos. Porém, a avaliação da escola e a reflexão sobre sua realidade não podem se esgotar nelas, que podem ser tomadas como o ponto de partida para a trajetória da escola rumo à sua avaliação institucional, que não pode prescindir de uma autoavaliação.

A avaliação externa é, nesse sentido, um processo e uma condição necessários para que se possam estabelecer e acompanhar metas qualitativas e quantitativas e verificar se estas últimas são atingidas. Com esse olhar, e não com o aquele descrito como accountability, essa avaliação, que deve ser articulada com outras modalidades, como são a avaliação interna e a avaliação institucional, é capaz de fomentar nas escolas e nas redes uma interpelação sistemática sobre a qualidade de suas práticas e dos seus resultados e reforçar a capacidade das escolas para desenvolverem a sua autonomia, regulando o funcionamento do sistema educativo.

Portanto, não se trata de desprezar as avaliações e tão pouco seus resultados, cabe, antes, analisar os processos avaliativos, objetivando compreender seus limites e ressaltar suas potencialidades, principalmente aquelas que podem contribuir com a construção de alternativas pedagógicas para as políticas e as escolas cumprirem suas funções junto à sociedade democrática, no sentido de oferecer educação pública de qualidade para todos seus alunos e alunas. É com este uso dos resultados das iniciativas avaliativas em curso no país, e não com a responsabilização que busca punir (FREITAS, 2011) profissionais da educação, que vamos criar condições para ampliar a qualidade do ensino.

Utilizar os dados do Ideb e das avaliações externas que o produzem, portanto, significa compreendê-los não como um fim em si mesmo, mas, sim, como oportunidade de associá-los às transformações necessárias no sentido de fortalecer a qualidade da escola pública democrática, que é aquela que se organiza para garantir o ensino-aprendizagem de qualidade para todos.

\section{Referências}

AFONSO, A. J. Avaliação educacional: regulação e emancipação. 4 ed. São Paulo: Cortez, 2009.

BONAMINO, A. Tempos de avaliação educacional: o Saeb, seus agentes, referências e tendências. Rio de Janeiro: Quartet, 2002.

BONAMINO, A.; SOUSA, S. M. Z. Três gerações de avaliação da educação básica no Brasil: interfaces com o currículo da/na escola. Educação e Pesquisa, São Paulo, v.38, n.2, p. 373-388, Abr./Jun. 2012. 
BRASIL. Presidência da República. Casa Civil. Subchefia para Assuntos Jurídicos. Decreto No 6.094, de 24 de abril de 2007. Dispõe sobre a implementação do Plano de Metas Compromisso Todos pela Educação, pela União Federal, em regime de colaboração com Municípios, Distrito Federal e Estados, e a participação das famílias e da comunidade, mediante programas e ações de assistência técnica e financeira, visando à mobilização social pela melhoria da qualidade da educação básica. Disponível em: <http://www.planalto.gov.br/ccivil_03/_ato2007-2010/2007/decreto/d6094.htm>. Acesso em: 19 mar. 2015.

BRASIL. Presidência da República. Plano Nacional de Educação-PNE. Lei Federal 13.005 de 25 de junho de 2014. http://www.planalto.gov.br/ccivil_03/_Ato2011-2014/2014/Lei/L13005.htm Acesso em: 25 mar. 2015.

BRASIL. Ministério da Educação. Saeb - Apresentação. Disponível em: http://portal.inep.gov.br/web/saeb/semelhancas-e-diferencas Acesso em: 25 mar. 2015.

CASTRO, M. H. G. O desafio da qualidade. In: ITUASSU, A.; ALMEIDA, R. (Orgs.). O Brasil tem jeito? Educação, saúde, justiça e segurança. Vol.2. Rio de Janeiro: Jorge Zahar, 2007. p. 35-72.

COELHO, M. I. M. Vinte anos de avaliação da educação básica no Brasil: aprendizagens e desafios. Ensaio: Avaliação e Políticas Públicas em Educação, Rio de Janeiro, v.16, n.59, p. 229-258, Abr./jun. 2008.

DOURADO, L. F. (Coord.). A qualidade da educação: conceitos e definições. Brasília: MEC/Inep, 2007.

FERNANDES, R. Índice de Desenvolvimento da Educação Básica (Ideb). Brasília: Instituto Nacional de Estudos e Pesquisas Educacionais Anísio Teixeira (Inep), 2007. 26 p. (Série Documental. Textos para Discussão, 26).

FERNANDES, R. GREMAUD, A. P. Qualidade da educação: avaliação, indicadores e metas. In: VELOSO, F. et al. (Orgs.). Educação básica no Brasil: construindo o país do futuro. Rio de Janeiro: Elsevier, 2009. p. 213-238.

FRANCO, C.; ALVES, F.; BONAMINO, A. Qualidade do ensino fundamental: políticas, suas possibilidades, seus limites. Educação \& Sociedade, Campinas, v.28, n.100, especial, p.989-1014, Out. 2007.

FREITAS, D. N. T. A avaliação da educação básica no Brasil. Campinas: Autores Associados, 2007.

FREITAS, L. C. Responsabilização, meritocracia e privatização: conseguiremos escapar ao neotecnicismo? In: SEMINÁRIO DE EDUCAÇÃO BRASILEIRA, 3, 2011, Campinas. Anais... Campinas: UNICAMP/CEDES, 2011. http://www.cedes.unicamp.br/seminario3/luiz_freitas.pdf Acesso em: 25 mar. 2015.

SACRISTÁN, J. G. A avaliação no ensino. In: ; PÉREZ GÓMEZ, A. I. (Orgs.). Compreender e transformar o ensino. 4 ed. Tradução de Ernani F. da Fonseca Rosa. Porto Alegre: Artmed, 1998. p. 295-351. 
HADDAD, F. O Plano de Desenvolvimento da Educação: razões, princípios e programas. Brasília: Instituto Nacional de Estudos e Pesquisas Educacionais Anísio Teixeira, 2008. 23 p. (Série Documental. Textos para Discussão, 30).

NEVO, D. Avaliação por diálogos: uma contribuição possível para o aprimoramento escolar. In: TIANA, A. (Coord.). Anais do Seminário Internacional de Avaliação Educacional, 1a 3 de dezembro de 1997. Tradução de John Stephen Morris. Brasília: Instituto Nacional de Estudos e Pesquisas Educacionais, 1998.

OLIVEIRA, A. P. M. A Prova Brasil como política de regulação da rede pública do Distrito Federal. 2011. 276 f. Dissertação (Mestrado em Educação) - Universidade de Brasília, Brasília, 2011.

OLIVEIRA, R. P.; ARAUJO, G. C. Qualidade do ensino: uma nova dimensão da luta pelo direito à educação. Revista Brasileira de Educação, São Paulo, n. 28, p.5-23, Jan./Abr. 2005.

RISOPATRON, V. E. El concepto de calidad de la educación. Chile: Unesco/Orealc, 1991.

SAVIANI, D. O Plano de Desenvolvimento da Educação: análise do projeto do MEC. Educação \& Sociedade, Campinas, v. 28, n.100, especial, p.1231-1255, Out. 2007.

SOARES, J. F. Qualidade da educação: qualidade de escolas. VIANA, F.S. et al. (Orgs.). A qualidade da escola pública no Brasil. Belo Horizonte: Mazza, 2012. p.75-96.

SOUSA, S. M. Z. Avaliação do rendimento escolar como instrumento de gestão educacional. In: OLIVEIRA, D. (Org.). Gestão democrática da educação: desafios contemporâneos. Petrópolis: Vozes, 1997. p.264-283.

SOUSA, S. M. Z.; ARCAS, P. H. Implicações da avaliação em larga escala no currículo: revelações de escolas estaduais de São Paulo. Educação: Teoria e Prática, Rio Claro, v.20, n.35, p.181-199, Jul./Dez. 2010.

SOUSA, S. M. Z.; LOPES, V. V. Avaliação nas políticas educacionais atuais reitera desigualdades. Revista Adusp, São Paulo, s/v, n.46, p.53-59, Jan. 2010.

STOBART, G. Tiempos de pruebas: los usos y abusos de la evaluación. Traducción de Pablo Manzano Bernández. Madrid: Morata/Ministerio de Educación, 2010.

VIANNA, H. M. Fundamentos de um programa de avaliação educacional. Brasília: Liber Livro, 2005.

WEBER, S. Relações entre esferas governamentais na educação e PDE: o que muda? Cadernos de Pesquisa, São Paulo, v.38, n.134, p.305-318, Maio/Ago. 2008.

Recebido em: agosto 2013

Aprovado para publicação em: setembro 2014 
Educação: Teoria e Prática/ Rio Claro/ Vol. 25, n.48/ p. 67-79/ Jan-Abr. 2015. 